\title{
Contribuição do plasma rico em plaquetas na reparação óssea de defeitos críticos criados em crânios de camundongos
}

\author{
Platelet-rich plasma contribute to the process of bone repair of critical defects created in \\ the calvaria of mice
}

\author{
Betânia Souza Monteiro' Ricardo Junqueira Del Carlo"I Napoleão Martins Argôlo NetoII \\ Laila de Paula BonfáII Marlene Vargas Viloria" Cinthya Dessaune Neves ${ }^{\text {II }}$ \\ Pablo Herthel Carvalho ${ }^{\text {II }}$ Ana Flora Souza BritoII
}

\section{RESUMO}

No presente estudo, foram avaliados, de forma macro e microscópica, os resultados da aplicação do PRP em defeitos ósseos críticos de 6,0 $\mathrm{mm}$ de diâmetro confeccionados em calvária de 24 camundongos isogênicos C57BL/6 jovens, separados em dois grupos experimentais. O grupo controle não recebeu tratamento, e no grupo tratado foram depositados, no interior do defeito, 50,0 $\mu$ L plasma em gel contendo $1,0 \times 10^{9}$ plaquetas. Constatou-se que o gel de PRP autólogo depositado em defeitos críticos contribuiu positivamente para o processo de reparação óssea, mormente na fase inicial.

Palavras-chave: gel autólogo de plaquetas, reparação óssea, fatores de crescimento.

\section{ABSTRACT}

This study aimed to evaluate macro and microscopic results after PRP application in bone critical defects of $6.0 \mathrm{~mm}$ in diameter realized in cavarial of twenty-four young isogenic mice C57BL/6. Control group didn't receive treatment and in the treated group it was deposited 50.0 $\mu$ L of plasma gel containing $1.0 \times 10^{9}$ platelets in the defects. It was found that autologous PRP gel contributed positively to the bone repair process, especially in initial phase.

Key words: autologous platelet gel, bone repair, growth factors.

\section{INTRODUÇÃO}

A reparação óssea é um processo complexo que envolve a quimiotaxia e adesão de células indiferenciadas e jovens à matriz óssea desmineralizada com sequente proliferação e diferenciação em osteoblasto, seguida por uma fase de organização e estruturação tecidual. A participação de proteínas regulatórias coordenando a biologia celular e molecular da osteogênese está cada vez mais evidenciada na literatura (ANITUA et al., 2004). Entre essas proteínas, destacam-se os fatores de crescimento liberados pelo Plasma Rico em Plaquetas (PRP).

O PRP contribui para a reparação de tecidos, por meio da estimulação quimiotática promovida pela presença de citocinas, quimiocinas, proteínas sanguíneas e fatores de crescimento presentes (ANITUA et al., 2004). A sinalização realizada por meio desses fatores deve-se à interação com os receptores de membrana localizados na superfície das células-alvo, resultando em proliferação ou inibição celular, específica a cada situação reparadora (LENHARO \& COSSO, 2001; KANNO et al., 2005).

A investigação dos efeitos do PRP em gel na reparação de falhas criadas em crânio de camundongos justifica-se pela controvérsia, estabelecida em trabalhos recentes, acerca da função do PRP, na qual alguns fatores influenciariam negativamente sua eficácia na promoção da reparação óssea, como, por exemplo: o tipo do biomaterial associado, a espécie animal, o local de implantação e a forma de preparo e ativação do plasma (DEL CARLO et

IDepartamento de Veterinária, Centro Universitário Vila Velha (UVV), 29102-770, Vila Velha, ES, Brasil. E-mail: betania.monteiro@ uvv.br. Autor para correspondência.

IDepartamento de Veterinária, Universidade Federal de Viçosa (UFV), Viçosa, MG, Brasil.

IIIDepartamento de Veterinária, Universidade Estadual de Santa Catarina (UDESC), Lages, SC, Brasil. 
al., 2009; SILVA et al., 2009). Ademais, a reparação de defeitos cranianos ainda representa um desafio devido à pequena capacidade de deposição óssea nessa região e, objetivando solução, diversos substitutos ósseos e agentes reparadores vêm sendo utilizados (DEL CARLO et al., 1994; MONTEIRO et al., 2007).

Nesse contexto de resultados controversos e dificuldades experimentais, o PRP surge como alternativa, e o presente estudo teve por objetivo avaliar, por meio de análises macro e microscópicas, a contribuição do gel de PRP aplicado em defeitos críticos confeccionados em calvária de camundongos C57BL/ 6 jovens, no processo de reparação óssea.

\section{MATERIAL E MÉTODOS}

Animais de experimentação: foram utilizados 32 camundongos machos da linhagem C57BL/6 isogênicos, com peso corpóreo médio de $30,0 \mathrm{~g}$ e seis meses de idade. Oito animais foram doadores de sangue para a obtenção de PRP, e os demais 24 foram utilizados para a experimentação in vivo e separados em dois grupos experimentais iguais. Os animais foram alojados individualmente em gaiolas, sob fotoperíodo de 12 horas, com temperatura e umidade controladas, ruídos mínimos, e foram alimentados com ração sólida e água ad libitum.

Obtenção do PRP: oito animais foram anestesiados com isoflurano, em câmara de gás anestésica. Posteriormente, foi realizada toracotomia esternal, o ventrículo esquerdo foi puncionado com uma agulha de $25 \mathrm{G}$, e coletado todo o volume sanguíneo circulante, aproximadamente $2,5 \mathrm{~mL}$ de sangue por animal. O sangue foi transportado para tubo esterilizado contendo citrato de sódio e centrifugado, durante 5 minutos, com velocidade de 350G (1500rpm). Após a centrifugação, todo o plasma foi retirado (aproximadamente 55\% do volume do sangue total), transferido para um novo tubo esterilizado e novamente centrifugado por cinco minutos a $350 \mathrm{G}$. A fase mais superficial do plasma (metade do volume total de plasma) foi desprezada, permanecendo apenas a porção mais rica em plaquetas, sendo considerada para esse experimento a quantidade mínima de $1,0 \times 10^{6}$ plaquetas $\mu \mathrm{L}^{-1}$. O volume total do PRP foi submetido à contagem e distribuído em 12 tubos de centrífuga, cada um contendo $50,0 \mu \mathrm{L}$ de plasma acrescido de $25,0 \mu \mathrm{L}$ de gluconato de cálcio $10 \%$, que foram colocados em banho-maria, a $37^{\circ} \mathrm{C}$, até o plasma apresentar a consistência de gel (gelação do plasma). Após a formação do gel de PRP, os frascos foram vedados e levados ao centro cirúrgico, para posterior aplicação.
Experimentação in vivo: os 24 animais foram separados em dois grupos experimentais iguais, grupos controle (GC) e PRP (GP), por meio de sorteio. Antes do ato cirúrgico, os camundongos receberam antibioticoterapia profilática com enrofloxacina $(10,0 \mathrm{mg}$ $\left.\mathrm{kg}^{-1}, \mathrm{IM}\right)$ e medicação analgésica à base de morfina $\left(5,0 \mathrm{mg} \mathrm{kg}^{-1}, \mathrm{SC}\right)$, que perdurou por três dias e foi realizada a cada oito horas. Os camundongos foram submetidos à medicação pré-anestésica com xilazina $\left(5,0 \mathrm{mg} \mathrm{kg}^{-1}\right.$, IP) e indução e manutenção com anestésico inalatório isoflurano, em câmara de anestesia. Em seguida, foram tricotomizados na porção dorsal do crânio, submetidos à antissepsia da área tricotomizada com solução povidine-iodine e tiveram o campo operatório delimitado por pano esterilizado. A pele, o subcutâneo e a musculatura foram incisados sobre a crista sagital externa do crânio, desde a protuberância occipital até próximo aos olhos, aproximadamente $1,0 \mathrm{~cm}$ de comprimento, permitindo a exposição do osso parietal. Com auxílio de uma broca trefina de $6,0 \mathrm{~mm}$ de diâmetro externo, conectada a uma perfuratriz elétrica, na velocidade de 5000rpm e sob irrigação contínua com solução fisiológica, foi realizado um defeito na região parietal, com área aproximada de $28,3 \mathrm{~mm}^{2}$, com exposição das meninges, que foi mantida íntegra no fundo do defeito.

O grupo PRP teve o defeito preenchido com o $50,0 \mu \mathrm{L}$ de plasma em gel contendo $1,0 \times 10^{9}$ plaquetas, e o grupo controle não recebeu tratamento. Em ambos os grupos, foi colocada uma membrana cortical desmineralizada, de origem bovina, reabsorvível, com extensão de $0,7 \times 0,7 \mathrm{~cm}$, acima da falha e abaixo da pele. Posteriormente, a pele foi aproximada com fio monofilamentar não absorvível, em pontos simples separados.

Períodos de avaliações: três animais de cada grupo foram identificados, pesados e submetidos à eutanásia, por sobredosagem anestésica com tiopental sódico, nos dias 10, 30, 60 e 90 de pós-operatório. Mediante a confirmação do óbito dos animais, foi realizada a coleta de biópsias ósseas, envolvendo a região do defeito e a porção adjacente do osso receptor. $\mathrm{O}$ fragmento foi identificado, medido, fotografado e conservado em formaldeído $10 \%$ tamponado para posterior processamento histológico.

Avaliação macroscópica: consistiu na mensuração da área do defeito e no estabelecimento do percentual de reparação óssea (área inicial - área mensurada em cada período/área inicial), por meio de análise de fotografias digitais obtidas com escala de mensuração (régua/escalímetro), intensidade de luz e altura da máquina fotográfica digital constantes. As imagens digitais foram transferidas para um 
computador e analisadas por um programa específico, o IMAGELAB. O local e aspecto do defeito e a presença de crescimento ósseo também foram registrados.

Análise estatística: os resultados obtidos foram submetidos ao testes de Kolmogorov-Smirnov para verificação da distribuição de normalidade da variável percentual de reparação óssea. Foi estabelecida a média do percentual de reparação óssea em cada período avaliado e foi realizada a análise das amostras independentes mediante a aplicação do Teste t de Student. Para tanto, foi adotado um nível de rejeição da hipótese de nulidade de $5 \%(\mathrm{P} \leq 0,05)$.

Avaliação microscópica: o material coletado foi submetido a processamento histológico de rotina, incluído em parafina e cortado $(5,0 \mu \mathrm{m}$ de espessura), envolvendo toda a área do defeito e as bordas do osso receptor (corte longitudinais) e, posteriormente, foi corado por Hematoxilina e Eosina (H\&E). As amostras foram avaliadas quanto à presença e às características do tecido de preenchimento, por meio de análise histológica descritiva.

\section{RESULTADOS}

Na avaliação macroscópica dos espécimes, independente do grupo, não foi observado crescimento ósseo fora das margens receptoras e nem abaixo da meninge. Foi constatada ausência de fechamento total dos defeitos até o período final de avaliação e aderências entre cérebro, meninges e tecido de reparação. Observou-se tanto em GC, quanto em GP que o osso novo de preenchimento do defeito apresentava espessura inferior ao osso receptor circunvizinho e que, ao longo dos períodos de avaliações, as bordas perdiam suas características de perímetros circulares, tornando-se irregulares, com locais de maior preenchimento.
Por meio da análise da variável percentual de reparação óssea, verificou-se que houve diferenças estatísticas entre os dois grupos experimentais nos períodos 10, 60 e 90 dias, e os animais do GP apresentaram os melhores valores de reparação. No GP, o percentual de reparação ocorrido do dia inicial da lesão até os 10 primeiros dias foi o maior encontrado (35\%), e foi diminuindo ao longo dos dias (dia 11 aos 30 dias, 17\%; dia 31 aos 60 dias, 10\%; e dia 61 aos 90 dias, $5 \%$ ). No GC, o maior percentual foi verificado entre os dias 11 e $30(30 \%)$. A tabela 1 apresenta os valores do percentual médio de reparação óssea exibido por período de observação, para os animais agrupados nos grupos controle e tratado com PRP e os valores de $P$ oriundos do estudo estatístico.

Histologicamente, no GC, aos 10 dias, observou-se multiplicação celular com discreta formação óssea nas bordas do defeito e em direção ao centro. Foi verificada a presença de tecido de granulação, com infiltrado de células basofílicas, substituindo a região anteriormente ocupada pelo coágulo sanguíneo. A maioria das células que participavam do processo de reparação originou-se, principalmente, dos tecidos moles (periósteo e musculatura) presentes nas extremidades do defeito.

Aos 30 dias, em algumas amostras, percebeu-se maior formação óssea em comparação ao período anterior, com o novo tecido dispondo-se em ilhas circundadas por tecido de granulação e insinuando-se para o interior do defeito. Nesse momento, os vasos sanguíneos de permeio ao tecido de granulação estavam presentes em quantidade superior à observada aos 10 dias. Aos 60 e 90 dias, o crescimento ósseo foi progressivo em relação ao tempo de observação, com presença de medula óssea com células mononucleares entremeando a díploe óssea. Foi visualizada presença de células grandes,

Tabela 1 - Percentual médio de reparação óssea exibido por período de observação, para os animais dos grupos controle (GC) e tratado com PRP (GP), e valores de P calculados confrontando dados do percentual de preenchimento ósseo, por período, do tratamento realizado no GP versus tratamento realizado no GC.

\begin{tabular}{ccccc}
\hline Tratamento & Período (dias) & Médias das áreas $\left(\mathrm{mm}^{2}\right)$ & Percentual de reparação óssea $\left(\mathrm{mm}^{2}\right)$ & Valor de P calculado \\
\hline GC & 10 & 22,133 & 21,880 & 35,253 \\
GP & 10 & 18,344 & 51,069 & \\
GC & 30 & 13,863 & 52,852 & $\mathrm{P}=0,0216^{\mathrm{a}}$ \\
GP & 30 & 13,358 & 58,199 & $\mathrm{P}=0,2989$ \\
GC & 60 & 11,843 & 62,166 & \\
GP & 60 & 10,719 & 62,957 & $\mathrm{P}=0,0002^{\mathrm{a}}$ \\
GC & 90 & 10,495 & 67,542 & $\mathrm{P}=0,0285^{\mathrm{a}}$ \\
GP & 90 & 9,196 & \\
\hline
\end{tabular}

${ }^{\text {a }}$ valores estatisticamente significativos $-\mathrm{P}=0,05$. 
arrendondadas, com citoplasma eosinofílico e núcleo basofílico, sendo sugestivas de megacariócitos.

A angiogênese observada no GP, em todos os períodos, foi maior que a observada no GC. No período inicial de 10 dias, foi visualizada a maior intensidade de neovascularização no grupo tratado, com presença de vasos sanguíneos congestos nas margens do defeito ósseo (Figura 1). Observou-se que a angiogênese diminuiu ao longo dos períodos, mantendo-se concentrada próxima às regiões de formação de novo osso. Também foi visualizado infiltrado celular constituído de células basofílicas substituindo a região anteriormente ocupada pelo coágulo sanguíneo, similar ao observado no GC.

No GP, aos 30 dias, a área de formação de novo osso, assim como o observado macroscopicamente, foi superior à encontrada aos 10 dias do GP e discretamente maior do que a visualizada no GC; contudo, estatisticamente, a osteogênese não foi significativa, em relação ao grupo controle. A deposição de matriz e formação de novo tecido ósseo aumentavam à medida que os períodos de avaliação avançavam. Também percebeu-se uma intensa movimentação celular provinda da região de tecidos moles adjacentes para o interior do defeito (Figura 2). Aos 60 e 90 dias, evidenciaram-se maiores quantidades de formações ósseas e organização tecidual. A quantidade e o amadurecimento do osso formado progrediram concomitantemente com o avançar do tempo de observação, e aos 90 dias já eram observados alguns ósteons.

Os tipos celulares presentes em ambos os grupos foram os mesmos. Foram visualizados osteoblastos cuboides em atividade de deposição de matriz óssea, se enfileirando nas margens da nova formação óssea, e discreta presença de osteoclastos, sobretudo visualizados aos 60 e 90 dias, próximos ao tecido osteoide formado. No GP, havia maior quantidade de osteoblastos e tecido osteoide se organizando, em comparação com o GC.

\section{DISCUSSÃO}

Verificou-se que o PRP em gel, como tratamento das falhas na porção parietal do crânio dos camundongos, acarretou maior formação óssea em relação ao grupo controle; contudo, ao final do período de avaliação aos 90 dias, os defeitos não estavam totalmente preenchidos. Tal característica evidencia a criação de um defeito critico na calvária do camundongo $(6,0 \mathrm{~mm})$, concordando com dados disponíveis na literatura que consideram críticos os defeitos com diâmetro superior a 2,7mm (SEO et al.,2008). Consequentemente, por mais que o tratamento com o

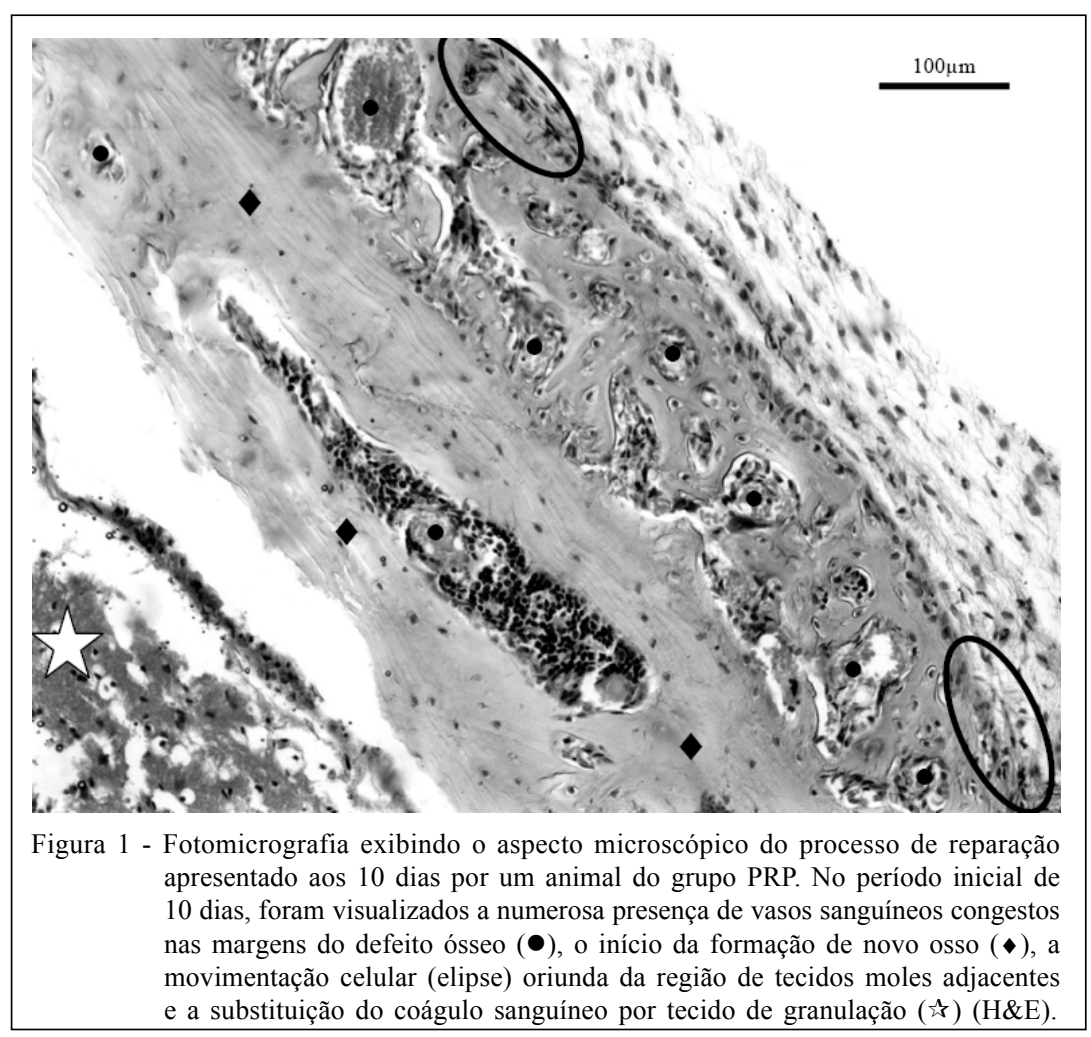

Ciência Rural, v.40, n.7, jul, 2010. 


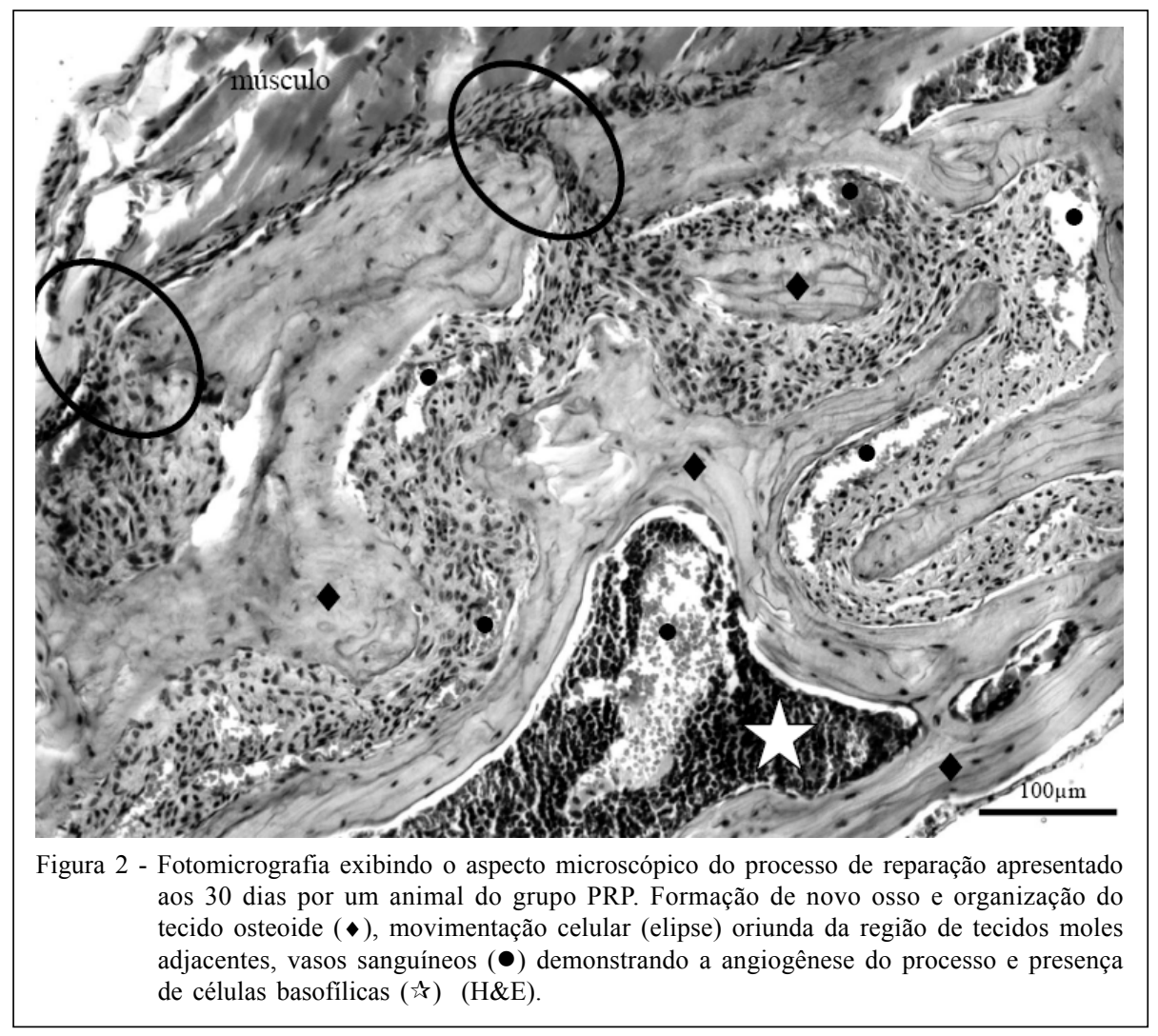

gel tenha incrementado o processo de reparação, ele não foi suficiente para promovê-la de forma total.

O estudo estatístico confirmou que o tratamento incrementou o processo de reparação óssea e acarretou maior crescimento de novo osso, sobretudo na fase mais precoce. Portanto, o efeito do gel de PRP ocorreu especialmente durante os estágios iniciais do processo de reparação, nos primeiros dias após a aplicação, mediante a liberação maciça dos fatores de crescimento presentes no plasma, com também encontraram MARX (2004).

A diferença estatisticamente significativa entre o GP e o GC, aos 10, 60 e 90 dias de avaliação, permite inferir que a liberação dos fatores de crescimento, providenciada pelo PRP, determinou maior recrutamento celular, ativação de células osteocomprometidas e consequente deposição de tecido ósseo a partir das margens da falha. Em acréscimo, a quantidade e o amadurecimento do osso formado progrediram concomitantemente com o avançar do tempo de observação, e aos 90 dias já eram observados alguns ósteons.

Outra inferência possível é que a quantidade

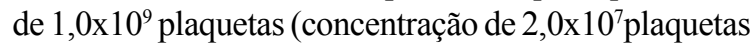
$\mu \mathrm{L}^{-1}$ ) foi adequada na promoção de recrutamento celular, concordando com KANNO et al. (2005), quando afirmaram que altas concentrações de plaquetas estimulam a proliferação e diferenciação de osteoblastos e com WEIBRICH et al. (2004), os quais reportaram que a concentração mínima para apropriado benefício biológico nos processos de reparação é de $1,0 \times 10^{7}$ plaquetas $\mu \mathrm{L}^{-1}$.

A membrana cortical desmineralizada reabsorvível, de origem bovina, utilizada acima dos defeitos em ambos os grupos, teve a finalidade de evitar a dispersão do material. Na avaliação realizada aos 30 dias em ambos os grupos, ela não estava mais presente, concordando com os dados do estudo piloto preliminar, realizado pelos autores, que constatou que ela não influencia o processo de reparação óssea, sendo totalmente reabsorvida num período de 15 dias. A não influência no processo de reparação foi o motivo que encorajou o uso dessa membrana no presente estudo.

De acordo com MARTIN (1997) e TSIROGIANNI et al. (2006), num processo de reparação tecidual, a primeira fase de reparação envolve a formação e organização do coágulo sanguíneo, durante as 24 horas iniciais. Após esse período, o coágulo começa a ser substituído e, por volta do nono ao décimo primeiro dia, a substituição por tecido de granulação 
está finalizada. Corroborando afirmação desses autores, principalmente no GP, foi visualizada a substituição do coágulo por células basofílicas, sobretudo nos primeiros 10 dias, e presença de tecido inflamatório constituído de células basofílicas.

A maior formação óssea e angiogênese exuberante, presente no GP, já haviam sido descritas por outros pesquisadores que afirmaram, em defesa ao uso do PRP, que, após a ativação do gel de plaquetas, ocorre a liberação de citocinas e fatores de crescimento essenciais para a progressão coordenada do processo de cicatrização, o aumento da vascularização e a regeneração tecidual (AGHALOO et al., 2004; MARX, 2004). Ademais, dentre os fatores de crescimento liberados pela ativação do plasma, destaca-se a presença do PDGF, que é considerado o primeiro fator de crescimento liberado na reparação tecidual, sendo secretado pelos macrófagos e pelas células endoteliais. Esse fator contribui para angiogênese, mitogênese de células da medula óssea e de pré-osteoblastos, e ativação da diferenciação de osteoblastos maduros que estimularão a deposição de proteínas na matriz óssea (MARX, 2004).

SILVA et al. (2009) utilizaram o PRP em gel na reparação óssea em calvária de coelhos e obtiveram bons resultados quanto à reparação. Porém, identificaram a presença de células gigantes e multinucleadas de permeio às novas formações ósseas. $\mathrm{Na}$ ocasião, consideraram a presença dessas células uma consequência de reação inflamatória do tipo corpo estranho, incitada pela tromboplastina comercial derivada do cérebro de coelho, usada na preparação do gel. De forma divergente, no estudo atual, o gel de plaquetas foi ativado por gluconato de cálcio $10 \%$, e a reação inflamatória observada não apresentava características de reação do tipo corpo estranho, não sendo visualizadas células gigantes e multinucleadas.

Outro achado de destaque, na avaliação microscópica, foi uma intensa mobilização celular da periferia da lesão, região de tecidos moles, para o centro da falha, principalmente no GP, demonstrando que houve contribuição positiva das células ósseas presentes no periósteo. SHIMIZU et al. (2001) já haviam demonstrado que, entre as células que constituem o periósteo, existem células progenitoras com potencial de se diferenciar em osteoblastos, passíveis de ser ativadas por estimulação física ou química, como nos casos de fraturas, inflamações e desenvolvimento de tumores, e que contribuem para a reparação.

\section{CONCLUSÃO}

Sob as condições nas quais foi desenvolvido o experimento, constata-se que o uso do gel de PRP depositado em defeitos críticos confeccionadas em calvária de camundongos C57BL/ 6 jovens contribui positivamente para o processo de reparação óssea, mormente na fase inicial.

\section{AGRADECIMENTOS}

Os autores agradecem à Fundação de Amparo à Pesquisa do Estado de Minas Gerais (FAPEMIG), à Coordenação de Aperfeiçoamento de Pessoal de Nível Superior (CAPES) e ao Conselho Nacional de Desenvolvimento Científico e Tecnológico $(\mathrm{CNPq})$, pelo apoio financeiro recebido.

\section{FONTES DE AQUISIÇÃO}

Membrana Genderm, Membrana biológica de origem bovina, Baumer, SP, Brasil.

Software IMAGELAB PRÓ PLUS ${ }^{\circledR}$, Média Cybernetics, Bethesda, MD, USA.

\section{COMITE DE ÉTICA E BIOSSEGURANÇA}

O projeto foi submetido ao Comitê de Ética em Experimentação Animal (CEEA) da Universidade Federal de Viçosa (UFV) e aprovado em março/2007, sob parecer número 46/2007, de acordo com as normas do Colégio Brasileiro de Experimentação Animal.

\section{REFERÊNCIAS}

AGHALOO, T.L. et al. Evaluation of platelet-rich plasma in combination with anorganic bovine bone in the rabbit cranium: a pilot study. International Journal of Oral \& Maxillofacial Implants, v.19, p.59-65, 2004.

ANITUA, E. et al. Autologous platelets as a source of proteins for healing and tissue regeneration. Thrombosis and haemostasis, v.91, p.4-15, 2004.

DEL CARLO, R.J. et al. Cranioplastia por interposição de auto-enxerto costal. III. Aspectos da enxertia óssea. Arquivo Brasileiro de Medicina Veterinária e Zootecnia, v.46, p.244-252, 1994.

DEL CARLO, R.J. et al. Aspectos microscópicos da reparação mediada por plasma rico em plaquetas e autoenxerto esponjoso em falhas ósseas experimentais no crânio de coelhos. Veterinária e Zootecnia, v.16, p.152-160, 2009. Disponível em: <http://www.fmvz.unesp.br/revista/volumes/vol16_n1/ VZ16_1(2009)_152-160.pdf $>$. Acesso em: 26 maio, 2009.

KANNO, T. et al. Platelet-rich plasma enhances human osteoblast-like cell proliferation and differentiation. Journal of Oral and Maxillofacial Surgery, v.63, p.362-369, 2005.

LENHARO, A.; COSSO, F. Fatores de crescimento: quando usar? Inovations Journal, v.5, p.21-25, 2001.

Ciência Rural, v.40, n.7, jul, 2010. 
MARTIN, P. Wound healing - aiming for perfect skin regeneration. Science, v.276, p.75-81, 1997. Disponível em: $<$ http://www.sciencemag.org/cgi/reprint/276/5309/75.pdf $>$. Acesso em: 26 maio, 2009. doi:10.1126/science.276.5309.75.

MARX, R.E. Platelet-rich plasma: evidence to support its use. Journal of Oral and Maxillofacial Surgery, v.2, p.489496, 2004.

MONTEIRO, B.S. et al. Proteínas morfogenéticas ósseas (BMPs) associadas a osso esponjoso autógeno na reparação de falhas experimentais na calota craniana de coelhos. Arquivo Brasileiro de Medicina Veterinária e Zootecnia, v.59, p.745-751, 2007.

SEO, B.M. et al. SHED repair critical-size calvarial defects in mice. Oral Diseases, v.14, p.428-434, 2008. Disponível em: <http://www3.interscience.wiley.com/cgi-bin/fulltext/ 119877726/PDFSTART>. Acesso em: 29 maio, 2009.
SHIMIZU, T. et al. Osteoblastic differentiation of periosteumderived cells is promoted by physical contact with the bone matrix in vivo. Anatomical Record, v.264, p.72-81, 2001.

SILVA, P.S.A. et al. Plasma rico em plaquetas (PRP) associado ou não ao osso esponjoso autógeno no reparo de falhas ósseas experimentais. Ciência Rural, v.39, p.129-134, 2009.

TSIROGIANNI, A.K. et al. Wound healing: immunological aspects. Injury, v.375, p.S5-S12, 2006. Disponível em: < http://www.sciencedirect.com/science/sdarticle.pdf $>$. Acesso em: 27 de maio, 2009. doi:10.1016/j.injury.2006.02.035.

WEIBRICH, G. et al. Effect of platelet concentration in platelet-rich plasma on peri-implant bone regeneration. Bone, v.34, p.665-671, 2004. 